\title{
Nano- $\mathrm{CaCO}_{3}$ synthesis by jet flow
}

\section{Eda Ulkeryildiz, Sevgi Kilic, Ekrem Ozdemir*}

Department of Chemical Engineering, Izmir Institute of Technology, Urla, Izmir, 35430, Turkey

\section{H I G H L I G H T S}

- We showed that the $\mathrm{Ca}(\mathrm{OH})_{2}$ solution is a natural stabilized for the newly synthesized nano- $\mathrm{CaCO}_{3}$ particles.

- A new methodlogy was introduced to produce stable hollow nano- $\mathrm{CaCO}_{3}$ particles.

- This methodlogy can be modified for drug loading within inorganic $\mathrm{CaCO}_{3}$ particles.

\section{A R T I C L E I N F O}

\section{Article history:}

Received 14 July 2016

Received in revised form 14 October 2016

Accepted 15 October 2016

Available online 17 October 2016

\section{Keywords:}

Hollow

Nano

$\mathrm{CaCO}_{3}$

$\mathrm{Ca}(\mathrm{OH})_{2}$

Stability

Zeta potential

\section{G R A P H I C A L A B S T R A C T}

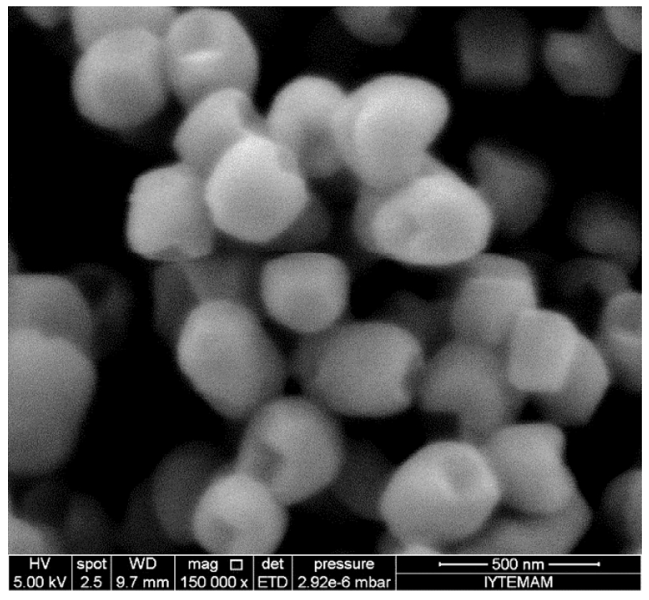

\section{A B S T R A C T}

A new methodology was introduced to produce hollow nano calcite particles in homogenous size distribution without aggregation. The design consisted of a jet flow system in which the crystallization region was separated from the stabilization region. The newly produced nano $\mathrm{CaCO}_{3}$ particles of about $140 \mathrm{~nm}$ were removed from the crystallization region as quickly as possible into the stabilization region before aggregation or crystal growth. In the stages of crystallization, the particles started to dissolve from their edges which opened-up the pores inside the particles. At the late stages of crystallization, the open pores closed. These particles were stable in $\mathrm{Ca}(\mathrm{OH})_{2}$ solution and no aggregation was detected. Different particles with different morphologies can be produced by adjusting the stages in the crystallization.

(C) 2016 Elsevier B.V. All rights reserved.

\section{Introduction}

Calcium carbonate $\left(\mathrm{CaCO}_{3}\right)$ is one of the most abundant minerals in nature and widely used as filling material in various industries

\footnotetext{
* Corresponding author.

E-mail addresses: ekost4@gmail.com, ekremozdemir@iyte.edu.tr (E. Ozdemir).
}

in order to decrease the product costs and to improve some of the mechanical properties of the composite materials [1-3]. The enhancement in the physical and mechanical properties of the polymeric composite materials is more pronounced when the particles are in nano sizes [4]. Obtaining $\mathrm{CaCO}_{3}$ particles in nano sizes with homogeneous size distribution and different morphologies is difficult and rare in the literature due to agglomeration of newly 
synthesized clusters [5-8], which is related to the surface potential of the colloidal $\mathrm{CaCO}_{3}$ particles [9-12].

The early mechanism for the $\mathrm{CaCO}_{3}$ formation was specified as a sudden nucleation burst in a supersaturated solution followed by diffusional growth of the nuclei to form identical particles [13]. Recent $\mathrm{CaCO}_{3}$ crystallization mechanisms identified intermediate precursors before formation of vaterite and calcite morphologies as in the chemical method [1,8,13-17]. For instance, Gebauer et al. [5] identified the stable prenucleation ion clusters even in under-saturated $\mathrm{CaCO}_{3}$ solution. Pouget et al. [8] showed the template-directed crystal formation from prenucleation clusters. These clusters are charged particles in equilibrium with their ions and they can grow or collide to produce $\mathrm{CaCO}_{3}$ nuclei. Therefore, certain additives were introduced into the crystal growing medium to alter the surface charge of the growing nuclei and to inhibit the $\mathrm{CaCO}_{3}$ growth [18-20]. Although the classical definition of crystallization explains the crystallization mechanisms in the macroscopic scales, it is still not helpful to develop processes to control the particle size and crystal morphologies.

Nano $\mathrm{CaCO}_{3}$ particles can be produced when the newly produced particles are stabilized by adjusting the surface potential of the particles. Particles with zeta potentials more positive than $+30 \mathrm{mV}$ or more negative than $-30 \mathrm{mV}$ are considered stable [21]. There is an uncertainty on the zeta potential values for the $\mathrm{CaCO}_{3}$ in the literature; sometimes positive, sometimes negative, and sometimes variable zeta potential values were measured [11]. The zeta potential for $\mathrm{CaCO}_{3}$ was reported to be about $-10 \mathrm{mV}$ [22] indicating that the newly produced $\mathrm{CaCO}_{3}$ clusters are naturally unstable. It is the reason why newly formed particles were aggregated and formed micron sized particles [7,23-28]. It was understood that the surface potential for $\mathrm{CaCO}_{3}$ is affected by various parameters such as aging [22], temperature [29], additives [30,31], surface modifiers [9], and ions [10,12]. For instance, the zeta potential for $\mathrm{CaCO}_{3}$ was positive when $\mathrm{Ca}^{++}$ions were in excess in the solution, and it was negative when $\mathrm{CO}_{3}=$ ions were in excess in the solution [10,12,22]. Therefore, the presence of other ions, called the potential determining ions (PDI) [11] such as crystal lattice ions, surface hydrolysis ions, and adsorbing ions in solution, are highly important for the production of stable nano $\mathrm{CaCO}_{3}$ particles.

We have recently reported that the $\mathrm{Ca}(\mathrm{OH})_{2}$ solution is a natural stabilizer for the newly produced $\mathrm{CaCO}_{3}$ particles $[32,33]$. Here, we report that when the newly produced nano clusters were removed as quickly as possible from the crystallization medium into the $\mathrm{Ca}(\mathrm{OH})_{2}$ solution as the stabilization medium, stable nano $\mathrm{CaCO}_{3}$ particles can be produced with homogenous size distribution.

\section{Materials and methods}

\subsection{Materials and methods}

Calcium hydroxide was purchased from Merck with a purity of $96 \%$ of which $3 \%$ was $\mathrm{CaCO}_{3}$, and $1 \%$ was other impurities (mainly $0.05 \%$ of $\mathrm{Na}, \mathrm{K}, \mathrm{Fe}, \mathrm{Sr} ; 0.5 \%$ of $\mathrm{Mg} ; 0.01 \%$ of $\mathrm{SO}^{=}$, and $0.005 \%$ of $\left.\mathrm{Cl}^{-}\right) . \mathrm{CO}_{2}$ gas was purchased from Carbogas, Turkey with a purity of 99.99\%. Ultrapure water was obtained with a MilliQ(Millipore- Elix UV5/Milli-Q) water purification system with a purity of $18.2 \mu \Omega$ at $25^{\circ} \mathrm{C}$.

\subsection{Nano $\mathrm{CaCO}_{3}$ synthesis}

An experimental set up was designed to quickly remove newly synthesized $\mathrm{CaCO}_{3}$ particles from the crystallization region into the $\mathrm{Ca}(\mathrm{OH})_{2}$ solution as shown in Fig. 1 . The new set up consisted of a $\mathrm{Ca}(\mathrm{OH})_{2}$ solution tank, a coil pipe with holes for $\mathrm{CO}_{2}$ injection, a mechanical stirrer, a pump for liquid circulation, and a data acqui-

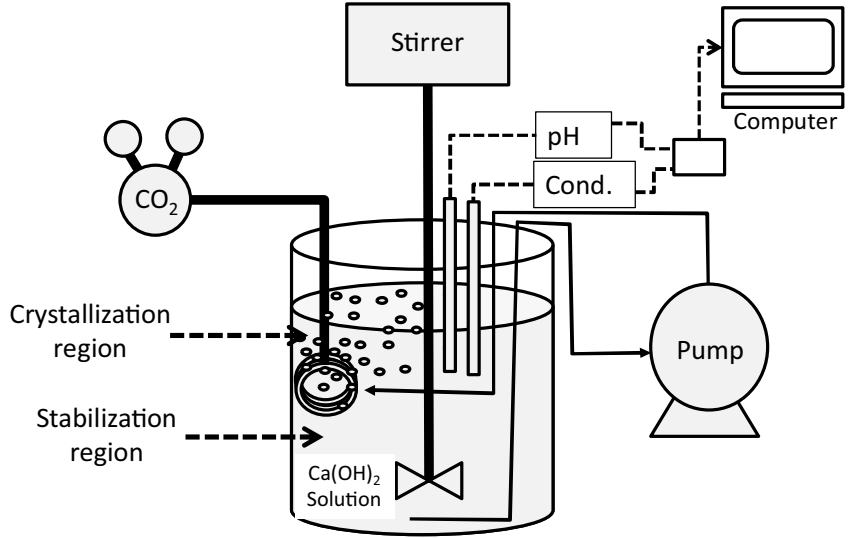

Fig. 1. Experimental set up.

sion system to monitor the $\mathrm{pH}$ and conductivity of the solution in the tank. The coil was placed at the upper corner of the tank so that a "crystallization region" and a "stabilization region" were created. $\mathrm{A} \mathrm{Ca}(\mathrm{OH})_{2}$ solution of 12 liters was prepared with a concentration of $15 \mathrm{mM}$ and used in the $\mathrm{CaCO}_{3}$ crystallization. The stirring rate of the solution was $800 \mathrm{RPM}$. The $\mathrm{CO}_{2}$ flow rate through the bubbling coils was $420 \mathrm{ml} / \mathrm{min}$. When the $\mathrm{CO}_{2}$ bubbles were formed at the crystallization region in the solution, they were travelled to the surface of the solution in the tank and escaped to the atmosphere under the influence of buoyancy. The pump withdrawn the $\mathrm{Ca}(\mathrm{OH})_{2}$ solution from the bottom of the tank and injected onto the coil pipe through a nozzle to create a jet on the $\mathrm{CO}_{2}$ bubbling coil. Therefore, the newly produced tiny nano particles were removed from the crystallization region into the stabilization region before any aggregation or crystal growth. $\mathrm{pH}$ and conductivity values were monitored through the crystallization. When $\mathrm{pH}$ reached to about 7.0 , the crystallization was terminated.

\subsection{Sample preparation and characterization}

About $1 \mathrm{ml}$ of sample was withdrawn from the solution into a UV cuvette and size and size distribution were measured by dynamic light scattering (DLS) method using particle size analyzer (Malvern nano ZS model). A $1 \mathrm{ml}$ of sample was also withdrawn from the solution into a zeta cell and zeta potential values were measured by the Malvern Zeta Sizer.

At certain time interval, precipitates were separated from sampled solutions by centrifugation (Universal 320-Hettich Zentrifugen) at $9000 \mathrm{RPM}$ for $20 \mathrm{~min}$. The particles were washed with acetone and dried at $103^{\circ} \mathrm{C}$ in an oven (Nüve FN 500) overnight. The morphologies of the $\mathrm{CaCO}_{3}$ crystals were analyzed using a scanning electron microscope (SEM) fitted with a field emission source (Philips XL 30 S FEG), operating at an accelerating voltage of $15 \mathrm{kV}$. The $\mathrm{CaCO}_{3}$ crystals were mounted on copper sample stubs with conducting carbon tape for SEM viewing.

The X-ray powder diffraction (XRD) measurements were carried out using a modified computer-controlled Philips X'Pert Pro $\mathrm{X}$-ray diffractometer. The crystal structure was determined using $\mathrm{Cu}$ Ka radiation ( $45 \mathrm{kV}$ and $40 \mathrm{~mA}$ ) equipped with a diffracted beam monochromator accelerating detector. The fine powder was packed into a zero background sample holder. The packed powder was introduced to detector as received. The diffraction pattern was recorded for $2 \theta$ from $10^{\circ}$ to $80^{\circ}$ and a $2 \theta$ step scan of $0.033^{\circ}$ was used. 


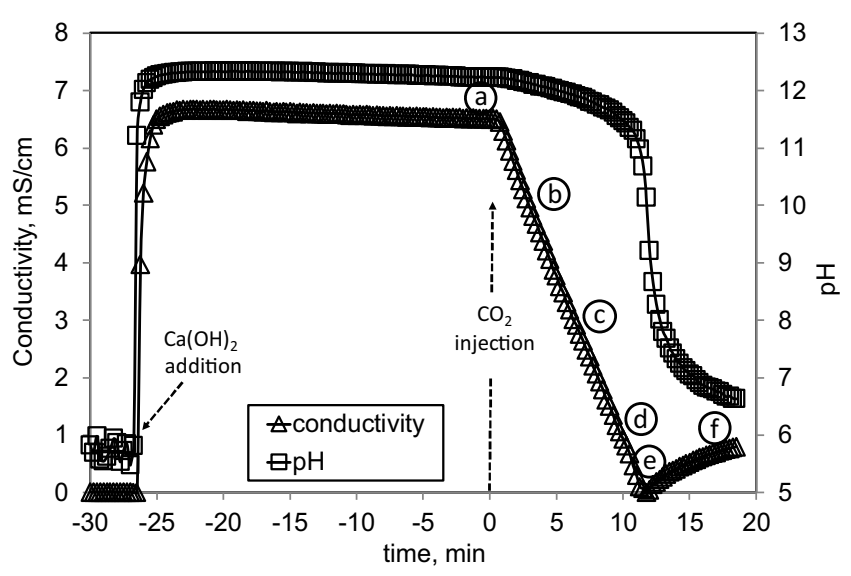

Fig. 2. $\mathrm{pH}$ and conductivity values during crystallization of $\mathrm{CaCO}_{3}$ in a jet flow system. Samples were taken at the specified time intervals.

\section{Results and discussion}

We have recently shown that the zeta potential of $\mathrm{CaCO}_{3}$ particles is more than $+30 \mathrm{mV}$ in $\mathrm{Ca}(\mathrm{OH})_{2}$, solution where they must be stable so that nano $\mathrm{CaCO}_{3}$ particles could be synthesized without aggregation [32,33]. Much smaller but aggregated $\mathrm{CaCO}_{3}$ particles were produced when the $\mathrm{CO}_{2}$ injection rates were higher. The present experimental methodology was designed to stabilize the newly generated nano $\mathrm{CaCO}_{3}$ crystalline particles in $\mathrm{Ca}(\mathrm{OH})_{2}$ solution at high $\mathrm{CO}_{2}$ flow rates. Our new design is based on formation of a jet flow on the newly synthesized nano clusters to separate them from the crystallization region into the stabilization region as quickly as possible before they proceed into aggregation. As shown in Fig. 1, the $\mathrm{CO}_{2}$ gas was supplied through the orifices on the coil pipe. As soon as the $\mathrm{CO}_{2}$ bubbles were released into the $\mathrm{Ca}(\mathrm{OH})_{2}$ solution, $\mathrm{CaCO}_{3}$ clusters were synthesized either on the $\mathrm{CO}_{2}$ bubbles or at the vicinity of these gas bubbles where the $\mathrm{HCO}_{3}{ }^{-}$and $\mathrm{CO}_{3}=$ concentrations are the highest due to $\mathrm{CO}_{2}$ dissolution. Because the newly synthesized nano clusters are in charged form, they are vulnerable to aggregate to form polycrystalline nano particles. The jet flow therefore removes these tiny nano particles from the crystallization region and distributes them into the rest of the $\mathrm{Ca}(\mathrm{OH})_{2}$ solution where they become stabilized.

Fig. 2 shows $\mathrm{pH}$ and conductivity values during the progress in the $\mathrm{CaCO}_{3}$ crystallization in jet flow stirred reactor. As shown in figure, before the $\mathrm{CO}_{2}$ injection, the conductivity and $\mathrm{pH}$ values for pure water were constant at $0.90 \mu \mathrm{s} / \mathrm{cm}$ and 5.5 , respectively. When $\mathrm{Ca}(\mathrm{OH})_{2}$ were added into the pure water, $\mathrm{pH}$ was reached to 12.5 and conductivity was reached to $6.6 \mathrm{mS} / \mathrm{cm}$ and the solution was fully stabilized in about $10 \mathrm{~min}$. Further stirring was conducted in order to fully dissolve the $\mathrm{Ca}(\mathrm{OH})_{2}$, if any [34]. As shown in the figure, the conductivity values decrease almost linearly as the $\mathrm{CO}_{2}$ injection was steady at $420 \mathrm{ml} / \mathrm{min}$. A slight decrease in $\mathrm{pH}$ were observed at the early stage of crystallization. The decrease in conductivity was related to the consumption of $\mathrm{Ca}^{++}$ions in the solution [32]. It took almost $11 \mathrm{~min}$ at which the conductivity value reached to about zero. Decrease in conductivity to about $0 \mathrm{mS} / \mathrm{cm}$ value indicated that almost all of $\mathrm{Ca}^{++}$ions were consumed in the solution. At this stage, a steep decrease in $\mathrm{pH}$ was observed from about 11 to about 7 due to an increase in $\mathrm{H}^{+}$and $\mathrm{HCO}_{3}{ }^{-}$ion concentrations in the solution as a result of $\mathrm{CO}_{2}$ dissolution. The $\mathrm{pH}$ values were always greater than 11.0 during the early stages of the $\mathrm{CaCO}_{3}$ crystallization. At the late stage, the decrease in $\mathrm{pH}$ values resulted in the dissolution of $\mathrm{CaCO}_{3}$ particles in the solution, which yielded the conductivity to increase back again in the solution. The crystallization was terminated when $\mathrm{pH}$ reached to about 7.0. Samples were taken at the specified time intervals as shown in the figure.
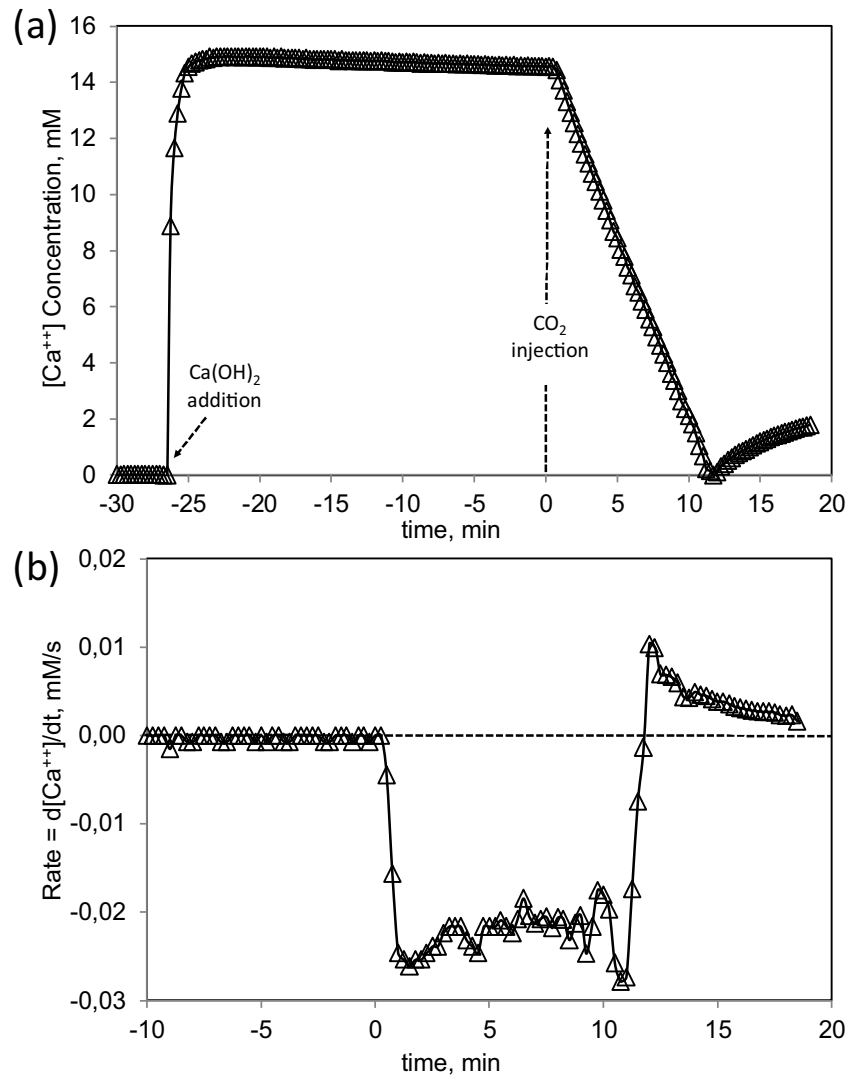

Fig. 3. (a) Estimated $\mathrm{Ca}^{++}$ion concentrations during crystallization in a jet flow system. (b) Calculated $\mathrm{Ca}^{++}$consumption rates during $\mathrm{CaCO}_{3}$ crystallization.

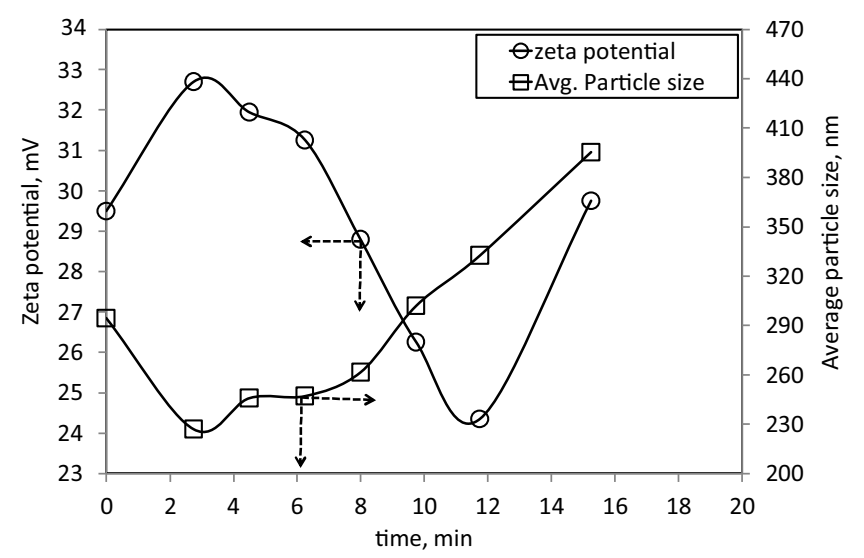

Fig. 4. Zeta potential and average particle size of the particles produced in jet flow stirred reactor.

The $\left[\mathrm{Ca}^{++}\right]$ion concentrations can be estimated from the conductivity values. We have shown that the measured conductivity values are linearly related to the $\left[\mathrm{Ca}(\mathrm{OH})_{2}\right]$ concentration up to its solubility limit of about $20 \mathrm{mM}$ [32].

Conductivity $=0.4268\left[\mathrm{Ca}(\mathrm{OH})_{2}\right]$

where conductivity is in $\mathrm{mS} / \mathrm{cm}$ and $\left[\mathrm{Ca}(\mathrm{OH})_{2}\right]$ is in $\mathrm{mM}$, which is also in very good agreement with Burns et al. [35]. Since $1 \mathrm{~mol}$ of $\left[\mathrm{Ca}^{++}\right]$ion was produced from $1 \mathrm{~mol}$ of $\mathrm{Ca}(\mathrm{OH})_{2}$ dissolved, the $\left[\mathrm{Ca}^{++}\right]$ion concentration could be estimated form the linearity of $\left[\mathrm{Ca}(\mathrm{OH})_{2}\right]$ concentrations up to its solubility limit.

The $\left[\mathrm{Ca}^{++}\right]$ion concentrations estimated from Eq. (1) were shown in Fig. 3a. Theoretically, $15 \mathrm{mM}\left[\mathrm{Ca}^{++}\right]$ion concentration would be obtained when a stoichiometric $15 \mathrm{mM}$ of $\mathrm{Ca}(\mathrm{OH})_{2}$ was 

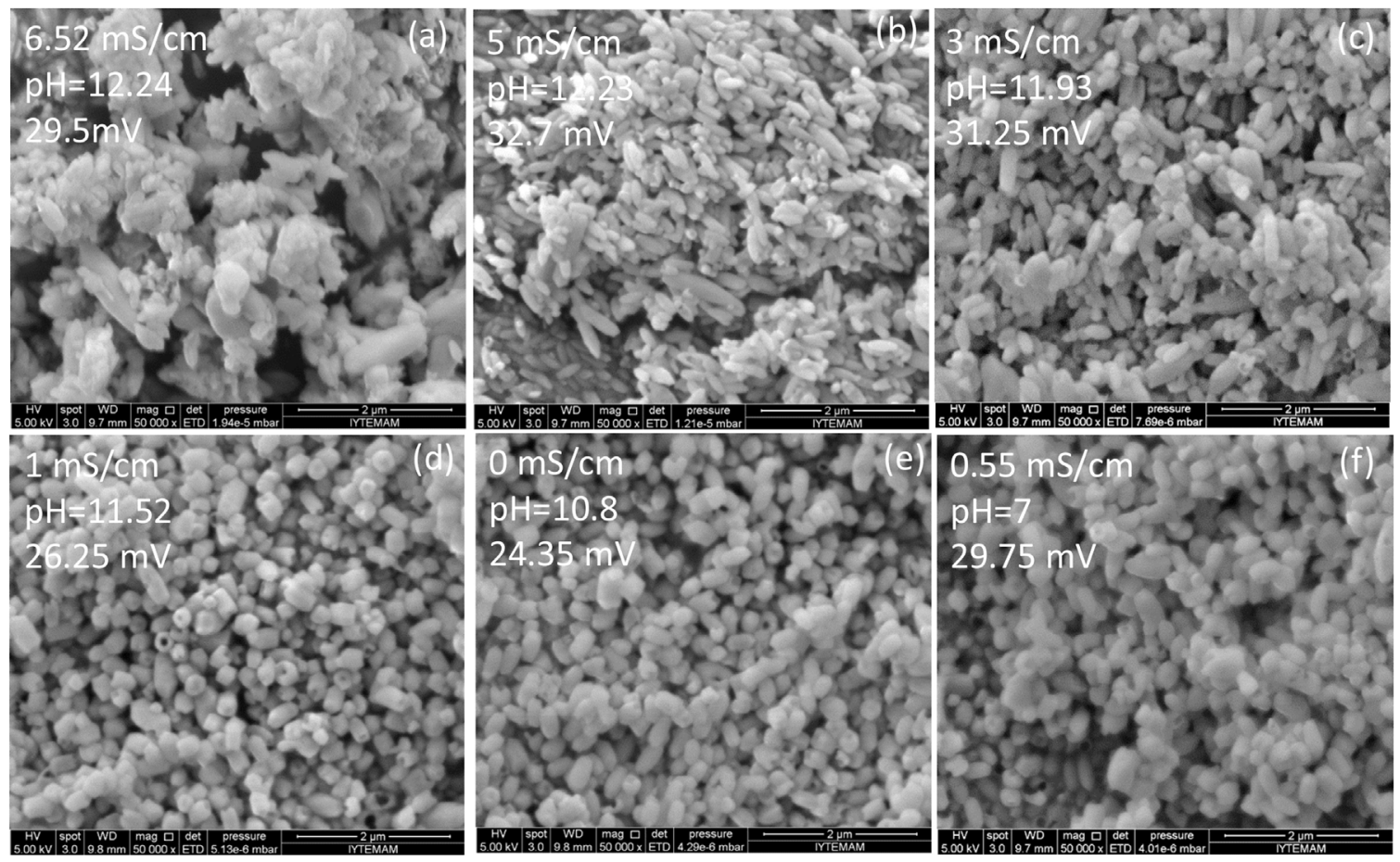

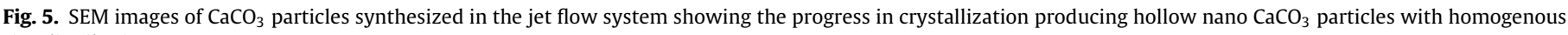
size distribution.

dissolved in ultrapure water. As shown in the figure, the $\left[\mathrm{Ca}^{++}\right]$ ion concentration was estimated to be about $15 \mathrm{mM}$ and started to decrease as soon as the $\mathrm{CO}_{2}$ bubbles were injected through the coil into the solution. Because the $\mathrm{CO}_{2}$ bubbles were too many and its injection rate was faster, it took almost $11 \mathrm{~min}$ to consume all $\mathrm{Ca}^{++}$ions in the solution. Fig. 3b shows the $\mathrm{Ca}^{++}$ion consumption rates calculated from the slope of the $\mathrm{Ca}^{++}$ion consumption curve. As can be seen in the figure, the $\mathrm{Ca}^{++}$ion consumption rate was estimated to be about $24 \pm 4 \mu \mathrm{M}$ /s during crystallization as a result of $\mathrm{CO}_{2}$ injection. The $\mathrm{Ca}^{++}$ion consumption rate can be related to the $\mathrm{Ca}(\mathrm{OH})_{2}$ consumption rate, $\mathrm{CaCO}_{3}$ crystallization rate, and $\mathrm{CO}_{2}$ consumption rate according to the overall reaction for $\mathrm{CaCO}_{3}$ crystallization.

$$
\mathrm{Ca}(\mathrm{OH})_{2}+\mathrm{CO}_{2} \rightarrow \mathrm{CaCO}_{3}+\mathrm{H}_{2} \mathrm{O}
$$

The $\mathrm{CO}_{2}$ consumption rate was calculated to be about $0.29 \pm 0.05$ mmole/s in 121 of $\mathrm{Ca}(\mathrm{OH})_{2}$ solution, which is in good agreement with the literature [36-38]. The decrease in the $\mathrm{Ca}^{++}$concentration indicate also that $\mathrm{Ca}^{++}$ions were consumed in nano crystal formation and attached to the surfaces of the newly produced solid nano particles, which help to stabilize them in the solution with a dissolution-recrystallization mechanism [1,26,27,39]. Upon consumption of all $\mathrm{Ca}^{++}$ions, the further injection of $\mathrm{CO}_{2}$ caused the dissolution of the newly synthesized $\mathrm{CaCO}_{3}$ particles, which started to increase the $\mathrm{Ca}^{++}$ion concentration in the solution so that the net $\mathrm{Ca}^{++}$consumption rate became positive.

Fig. 4 shows the zeta potential and average particle size of the particles produced during the progress of the crystallization. As shown in the figure, before the crystallization, the average particle size was about $300 \mathrm{~nm}$ and the zeta potential was measured to be $+29.5 \mathrm{mV}$. These particles were mostly the newly synthesized charged nano $\mathrm{CaCO}_{3}$ clusters distributed in the $\mathrm{Ca}(\mathrm{OH})_{2}$ solution. As soon as $\mathrm{CO}_{2}$ was injected into the solution, the average particle size was measured to be about $220 \mathrm{~nm}$ and zeta potential values were increased to $+33 \mathrm{mV}$. The zeta potential is an important indicator for the surface charge of the nano particles. Particles with zeta

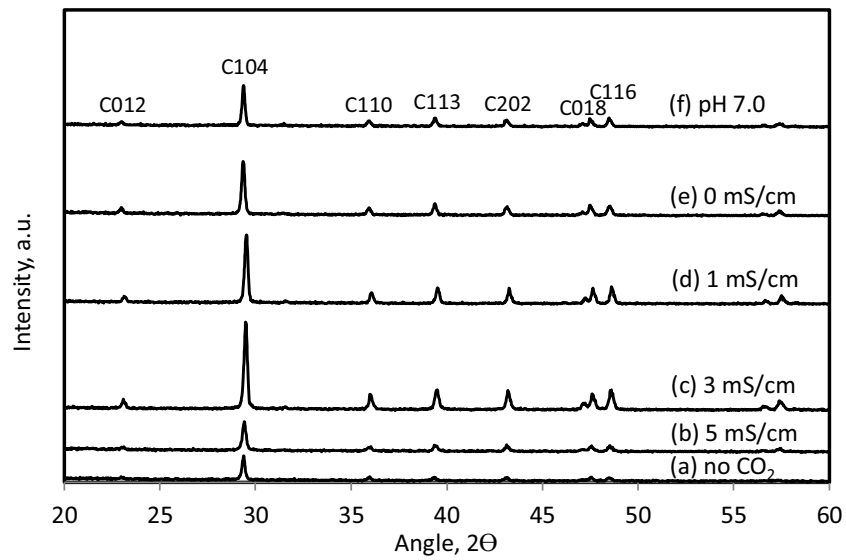

Fig. 6. XRD patterns for the $\mathrm{CaCO}_{3}$ particles obtained in the jet flow system.

potential more positive than $+30 \mathrm{mV}$ or more negative than $-30 \mathrm{mV}$ are considered to be stable [21]. The zeta potential for calcite was reported to be about $-10 \mathrm{mV}$ in the literature [40]. Therefore, the newly produced $\mathrm{CaCO}_{3}$ clusters are naturally unstable and undergo an aggregation in a supersaturated solution. As shown in the figure, the removal of nano particles from the crystallization region into the stabilization solution prohibited their aggregation and growth to larger particles. As the crystallization progressed, the average particle size was measured to increase to about $250 \mathrm{~nm}$ and the zeta potential values to about $+29 \mathrm{mV}$ indicating that newly produced stable particles appeared in the solution. At the late stages, when $\mathrm{Ca}^{++}$ions were consumed and $\mathrm{pH}$ started to decrease, the zeta potential value was measured to decrease to about $+24 \mathrm{mV}$. The low zeta potential value indicates that the surface coverage of $\mathrm{Ca}^{++}$ions on the particles became weak so that they were vulnerable to aggregate. As evidenced from the figure, the measured average particle size started to increase at these late stages. At the end of crystallization, the measured average particle size was about 

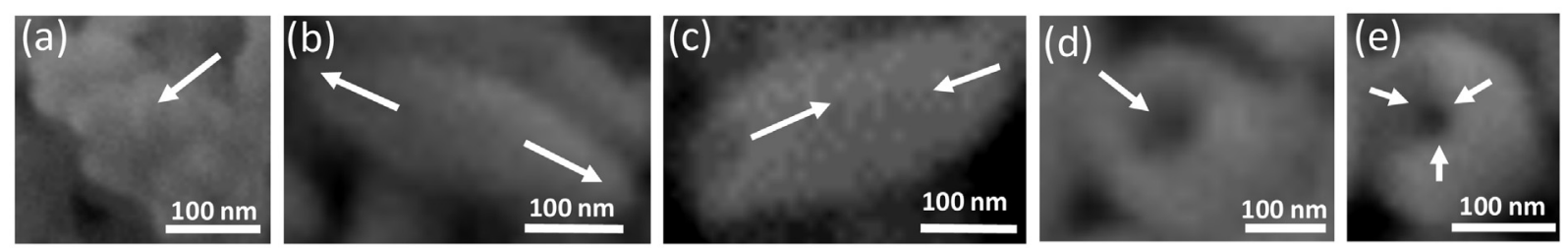

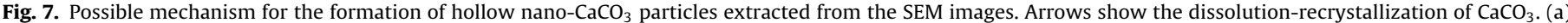

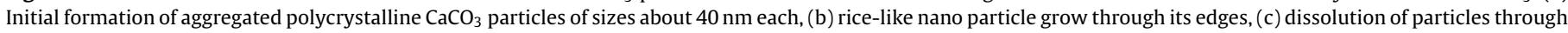

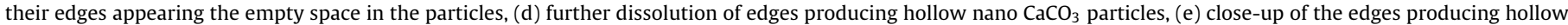
nano $\mathrm{CaCO}_{3}$ particles.
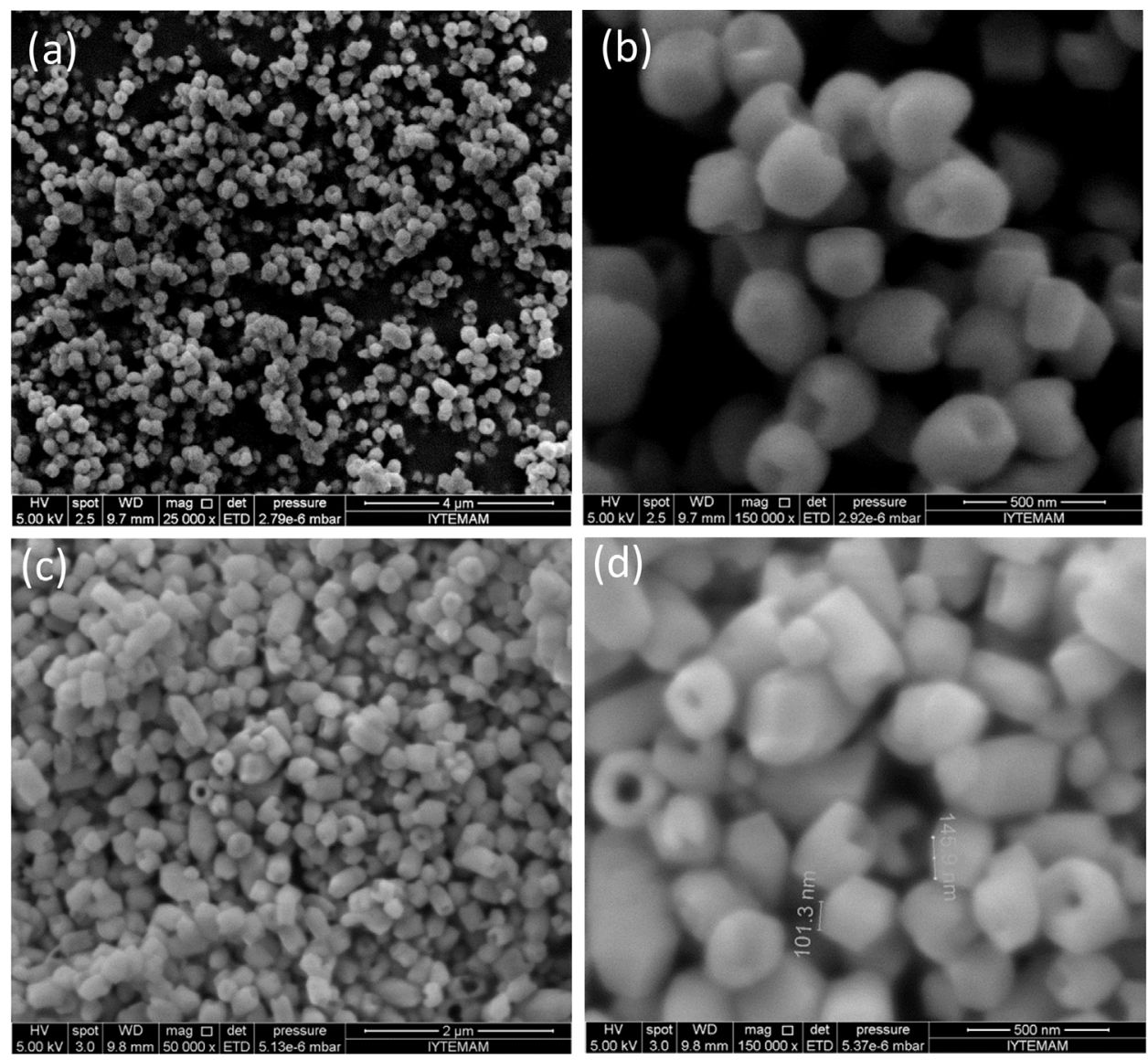

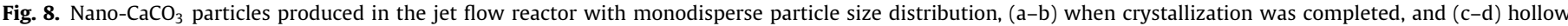
particles produced before consumption of $\mathrm{Ca}^{++}$ions in the $\mathrm{Ca}(\mathrm{OH})_{2}$ solution.

$400 \mathrm{~nm}$ and the zeta potential value was about $+30 \mathrm{mV}$ which was enough to stabilize the newly synthesized nano particles.

Fig. 5 shows the SEM images of the particles obtained at each step of crystallization in the jet flow stirred reactor. The conductivity, $\mathrm{pH}$ and zeta potential values were also shown in the images. As shown in figure, before the $\mathrm{CO}_{2}$ injection, at step (a), there was a flaky-like polycrystalline particles aggregated to form large clumps in the solution. These particles were aggregated on the $\mathrm{CaCO}_{3}$ residues remained in the $\mathrm{Ca}(\mathrm{OH})_{2}$ solution as the impurity. As soon as the $\mathrm{CO}_{2}$ bubbles were injected in the solution, rice-like $\mathrm{CaCO}_{3}$ particles formed with an average particle size of about $220 \mathrm{~nm}$ [33]. Not much aggregation was seen due to the stability effect of $\mathrm{Ca}(\mathrm{OH})_{2}$ solution [32], where the zeta potential values were higher than $+30 \mathrm{mV}$ [21]. As the crystallization progress, the particles was shown to grow slightly as their number were increased due to newly formed nano $\mathrm{CaCO}_{3}$ particles. As shown in the images, some of the particles were eroded due to dissolution in the solution. The dissolution rate was significant at step (c) and progressively increased through step (e). The dissolution of these particles discovered the fact that these particles were indeed in hollow shape with an empty space inside the particles. The growth rate and the dissolution rate were both higher at the edges of the rice-like particles because we think that the edges are the most energetic parts [41]. Interestingly, the hollow openings to the edges closed at the end of crystallization at step (f) as a result of the dissolution and recrystallization of $\mathrm{CaCO}_{3}$ particles in the solution $[1,26,27,39]$. The images at these steps indicate that the average particle size was about $140 \mathrm{~nm}$, and no aggregations was discerned due to their higher zeta potential values.

The new design jet flow stirred reactor produced nano particles with a very narrow size distribution. The produced particles were all calcite as evidenced from the XRD patterns as shown in Fig. 6 . The $2 \theta$ value at $29.468^{\circ}$, and the sharp peaks at the $d$-spacing $3.02864,1.9166$ and 1.8796 represent the well characterized (104) 
calcite form of $\mathrm{CaCO}_{3}$. In the present method, there was no any different peak detected for the nano $\mathrm{CaCO}_{3}$ particles other than calcite. Therefore, we have proven that when the particles were removed from the crystallization region as quickly as possible into the stabilization region, nano calcite particles with a narrow size distribution could be produced.

Fig. 7 shows SEM images of particles with a possible mechanism for the formation of hollow nano $\mathrm{CaCO}_{3}$ particles. As shown in Fig. $7 \mathrm{a}$, the newly produced $\mathrm{CaCO}_{3}$ particles would be $\mathrm{CaCO}_{3}$ polycrystalline particles $[5,8,42]$ of about $40 \mathrm{~nm}$ in size as calculated from the (104) peak of the XRD pattern of the $\mathrm{CaCO}_{3}$ particles using the Sheerer Equation [43]. These nano crystallite particles will aggregate with the available $\mathrm{Ca}^{++}, \mathrm{CO}_{3}{ }$, and other charged complex ions such as $\mathrm{CaHCO}_{3}{ }^{+}$and $\mathrm{Ca}(\mathrm{OH})^{+}$to form snowflake-like $\mathrm{CaCO}_{3}$ aggregates. The crystallites on these newly developed nano particles are not stable and vulnerable to dissolve. Fig. $7 \mathrm{~b}$ shows the rice-like nano $\mathrm{CaCO}_{3}$ particle grow through its edges which are the most energetic parts of the newly growing particle. $\mathrm{pH}$ is relatively lower around the $\mathrm{CO}_{2}$ bubbles where the concentrations of ionic species are higher. As the concentration of ionic species increases in the solution as a result of $\mathrm{CO}_{2}$ dissolution, the ions on the surfaces of the particles and in the solution undergoes an imbalance. Therefore, as shown in Fig. 7c, these particles disintegrate and dissolve in the solution starting from the edges. Decrease in $\mathrm{pH}$ further facilitates the dissolution of the particles, and as shown in Fig. 7d, hollow nano $\mathrm{CaCO}_{3}$ particles form. Increase in $\mathrm{Ca}^{++}$concentration as a result of the dissolution in the solution initiate the recrystallization of the particles. As shown in Fig. 7e, at the end of the crystallization, the edges of the hollow $\mathrm{CaCO}_{3}$ particles recrystallize almost closing the pores leaving an empty space inside.

Fig. 8 shows the SEM images of the nano- $\mathrm{CaCO}_{3}$ particles with a monodisperse particle size distribution without aggregation. When the crystallization was terminated at step (e) in Fig. 2 before fully consuming $\mathrm{Ca}^{++}$ions, hollow nano $\mathrm{CaCO}_{3}$ particles could be produced. When the $\mathrm{CO}_{2}$ injection was continued, almost filled nano- $\mathrm{CaCO}_{3}$ particles were produced. These hollow nano particles have numerous advantages. For instance, the bulk density of the hollow particles was measured about $0.95 \mathrm{~g} / \mathrm{cm}^{3}$ by packing them in a measure, where the density of the nano particles with closed pores was about $1.7 \mathrm{~g} / \mathrm{cm}^{3}$. Comparing to the crystal density of calcite at about $2.74 \mathrm{~g} / \mathrm{cm}^{3}$, the weight of the powder could be relatively reduced. The BET surface area of the open-pore and close-pore calcite was measured to be about $15 \mathrm{~m}^{2} / \mathrm{g}$ and $12 \mathrm{~m}^{2} / \mathrm{g}$, respectively. Due to weight reduction and high surface area, hollow nano $\mathrm{CaCO}_{3}$ particles could be used in composite materials, plastics, cement, paint, paper manufacturing, etc. [44-49]. In a recent study by our group, the hollow nano $\mathrm{CaCO}_{3}$ particles were employed in vacuum insulating panels (VIPs) as core material, which is important in energy saving applications. The hollow nano $\mathrm{CaCO}_{3}$ particles can also be used as sound and heat insulating materials in paints and coating. Drugs can be trapped within these hollow nano $\mathrm{CaCO}_{3}$ particles and used in drug delivery purposes [2,50-53].

\section{Conclusions}

The results of the present work clearly demonstrate that the aggregation of primary nano crystalline particles need to be prohibited in the very early stage of $\mathrm{CaCO}_{3}$ synthesis, otherwise, highly aggregated polycrystalline particles will grow in a heterogeneous particle size distribution. The zeta potential values of the newly produced $\mathrm{CaCO}_{3}$ particles were about $+30 \mathrm{mV}$ in $\mathrm{Ca}(\mathrm{OH})_{2}$ solution and therefore, $\mathrm{CaCO}_{3}$ particles are stable in $\mathrm{Ca}(\mathrm{OH})_{2}$ solution. Hollow nano $\mathrm{CaCO}_{3}$ particles were produced in homogenous size distribution without aggregation in the $\mathrm{Ca}(\mathrm{OH})_{2}$ solution when the newly produced nano $\mathrm{CaCO}_{3}$ particles were removed from the crystalliza- tion region into the stabilization region as quickly as possible in a jet flow stirred reactor. Dissolution was faster at the edges of the ricelike particles. At the late stages, when $\mathrm{Ca}^{++}$ions were consumed and $\mathrm{pH}$ decreased, recrystallization resulted in close-up of the edges of the particles leading to the formation of nano $\mathrm{CaCO}_{3}$ particles with almost closed pores at homogenous size distribution. XRD patterns of the particles indicated that the particles were all the calcite form of $\mathrm{CaCO}_{3}$. The hollow particles will be employed in sound and thermal barrier in vacuum insulating panels (VIPs) which were thought to be excellent candidate for energy saving materials.

\section{Acknowledgements}

The Scientific and Technological Research Counsel of Turkey (TUBITAK) is highly appreciated for the research grant with the project number 110M104.

\section{References}

[1] J. Rieger, M. Kellermeier, L. Nicoleau, Formation of nanoparticles and nanostructures-an industrial perspective on $\mathrm{CaCO}_{3}$, cement, and polymers, Angew. Chem. Int. Edit. 53 (2014) 12380-12396.

[2] N. Qiu, H.B. Yin, B.Z. Ji, N. Klauke, A. Glidle, Y.K. Zhang, H. Song, L.L. Cai, L. Ma, G.C. Wang, L.J. Chen, W.W. Wang, Calcium carbonate microspheres as carriers for the anticancer drug camptothecin, Mater. Sci. Eng. C: Mater. 32 (2012) 2634-2640.

[3] M.F. Butler, W.J. Frith, C. Rawlins, A.C. Weaver, M. Heppenstall-Butler, Hollow calcium carbonate microsphere formation in the presence of biopolymers and additives, Cryst. Growth Des. 9 (2009) 534-545.

[4] Y. Lin, H.B. Chen, C.M. Chan, J.S. Wu, High impact toughness polypropylene/CaCO3 nanocomposites and the toughening mechanism, Macromolecules 41 (2008) 9204-9213.

[5] D. Gebauer, A. Volkel, H. Colfen, Stable prenucleation calcium carbonate clusters, Science 322 (2008) 1819-1822.

[6] M. Kellermeier, D. Gebauer, E. Melero-Garcia, M. Drechsler, Y. Talmon, L. Kienle, H. Colfen, J.M. Garcia-Ruiz, W. Kunz, Colloidal stabilization of calcium carbonate prenucleation clusters with silica, Adv. Funct. Mater. 22 (2012) 4301-4311.

[7] S. Kilic, E. Ozdemir, Toward synthesis of $\mathrm{CaCO}_{3}$, J. Cryst. Growth (2015) (Submitted)

[8] E.M. Pouget, P.H.H. Bomans, J.A.C.M. Goos, P.M. Frederik, G. de With, N.A.J.M Sommerdijk, The initial stages of template-controlled $\mathrm{CaCO} 3$ formation revealed by cryo-TEM, Science 323 (2009) 1455-1458.

[9] R. Agnihotri, S.K. Mahuli, S.S. Chauk, L.S. Fan, Influence of surface modifiers on the structure of precipitated calcium carbonate, Ind. Eng. Chem. Res. 38 (1999) 2283-2291.

[10] L. Holysz, E. Chibowski, A. Szczes, Influence of impurity ions and magnetic field on the properties of freshly precipitated calcium carbonate, Water Res. 37 (2003) 3351-3360.

[11] P. Moulin, H. Roques, Zeta potential measurement of calcium carbonate, J. Colloid Interf. Sci. 261 (2003) 115-126

[12] S. Pourchet, I. Pochard, F. Brunel, D. Perrey, Chemistry of the calcite/water interface: influence of sulfate ions and consequences in terms of cohesion forces, Cem. Concr. Res. 52 (2013) 22-30.

[13] J.P. Andreassen, Formation mechanism and morphology in precipitation of vaterite-nano aggregation or crystal growth? J. Cryst. Growth 274 (2005) 256-264.

[14] J. Bolze, B. Peng, N. Dingenouts, P. Panine, T. Narayanan, M. Ballauff, Formation and growth of amorphous colloidal $\mathrm{CaCO} 3$ precursor particles as detected by time-resolved SAXS, Langmuir 18 (2002) 8364-8369.

[15] P. Bots, L.G. Benning, J.D. Rodriguez-Blanco, T. Roncal-Herrero, S. Shaw, Mechanistic insights into the crystallization of amorphous calcium carbonate (ACC), Cryst. Growth Des. 12 (2012) 3806-3814

[16] J.D. Rodriguez-Blanco, P. Bots, N.J. Terrill, S. Shaw, L.G. Benning, The mechanism of ACC nanoparticle transformation to vaterite, Geochim. Cosmochim. Acta 74 (2010) A876.

[17] C. Rodriguez-Navarro, K. Kudlacz, O. Cizer, E. Ruiz-Agudo, Formation of amorphous calcium carbonate and its transformation into mesostructured calcite, CrystEngComm 17 (2015) 58-72.

[18] Q. Liu, Q. Wang, L. Xiang, Influence of poly acrylic acid on the dispersion of calcite nano-particles, Appl. Surf. Sci. 254 (2008) 7104-7108.

[19] K.S. Seo, C. Han, J.H. Wee, J.K. Park, J.W. Ahn, Synthesis of calcium carbonate in a pure ethanol and aqueous ethanol solution as the solvent, J. Cryst. Growth 276 (2005) 680-687.

[20] Y. Sheng, B. Zhou, J.Z. Zhao, N. Tao, K.F. Yu, Y.M. Tian, Z.C. Wang, Influence of octadecyl dihydrogen phosphate on the formation of active super-fine calcium carbonate, J. Colloid Interf. Sci. 272 (2004) 326-329.

[21] M. Kes, Determination of the Particle Interactions-Rheology- Surface Roughness Relationshipmfor Dental Ceramics, Department of Chemistry, İzmir Institute of Technology, İzmir, 2007, pp. 111. 
[22] E. Chibowski, L. Hotysz, A. Szczes, Time dependent changes in zeta potential of freshly precipitated calcium carbonate, Colloid Surf. A 222 (2003) 41-54.

[23] J.G. Carmona, J.G. Morales, R. Rodriguez-Clemente,

Rhombohedral-scalenohedral calcite transition produced by adjusting the solution electrical conductivity in the system $\mathrm{Ca}(\mathrm{OH})(2)-\mathrm{CO} 2-\mathrm{H} 2 \mathrm{O}$, J. Colloid Interface Sci. 261 (2003) 434-440.

[24] J.G. Carmona, J.G. Morales, J.F. Sainz, R.R. Clemente, Morphological characteristics and aggregation of calcite crystals obtained by bubbling CO2 through a $\mathrm{Ca}(\mathrm{OH}) 2$ suspension in the presence of additives, Powder Technol. 130 (2003) 307-315.

[25] M. Kitamura, H. Konno, A. Yasui, H. Masuoka, Controlling factors and mechanism of reactive crystallization of calcium carbonate polymorphs from calcium hydroxide suspensions, J. Cryst. Growth 236 (2002) 323-332.

[26] J.D. Rodriguez-Blanco, S. Shaw, L.G. Benning, The kinetics and mechanisms of amorphous calcium carbonate (ACC) crystallization to calcite, via vaterite, Nanoscale 3 (2011) 265-271.

[27] C.Y. Tai, F.B. Chen, Polymorphism of $\mathrm{CaCO} 3$ precipitated in a constant-composition environment, AIChE J. 44 (1998) 1790-1798.

[28] G.W. Yan, J.H. Huang, J.F. Zhang, C.J. Qian, Aggregation of hollow CaCO3 spheres by calcite nanoflakes, Mater. Res. Bull. 43 (2008) 2069-2077.

[29] Jun Jiang Shao-Feng Chen, Lei Liu, Hong-Bin Yao, Yun-Hao Qiu, Min-Rui Gao, S.-H. Yu, Template-free polymorph discrimination and synthesis of calcium carbonate minerals, Chem. Commun. 39 (2009) 5853-5855.

[30] P.Q. Yuan, Z.M. Cheng, Z.M. Zhou, W.K. Yuan, R. Semiat, Zeta potential on the anti-scalant modified sub-micro calcite surface, Colloid Surf. A 328 (2008) 60-66.

[31] Shao-Feng Chen, Jian-Hua Zhu, Jun Jiang, Guo-Bin Cai, S.-H. Yu, Polymer-controlled crystallization of unique mineral superstructures, Adv. Mater. 22 (2010) 540-545.

[32] S. Kilic, G. Toprak, E. Ozdemir, Stability of $\mathrm{CaCO} 3$ in $\mathrm{Ca}(\mathrm{OH})(2)$ solution, Int. J. Miner. Process. 147 (2016) 1-9

[33] E. Ulkeryildiz, S. Kilic, E. Ozdemir, Rice-like hollow nano- $\mathrm{CaCO}_{3}$ synthesis, J. Cryst. Growth 450 (2016) 174-180.

[34] K. Johannsen, S. Rademacher, Modelling the kinetics of calcium hydroxide dissolution in water, Acta Hydroch. Hydrob. 27 (1999) 72-78.

[35] J.R. Burns, J.J. Jachuck, Monitoring of $\mathrm{CaCO} 3$ production on a spinning disc reactor using conductivity measurements, AIChE J. 51 (2005) 1497-1507.

[36] R.Y. Lin, J.Y. Zhang, Y.Q. Bai, Mass transfer of reactive crystallization in synthesizing calcite nanocrystal, Chem. Eng. Sci. 61 (2006) 7019-7028.

[37] F. Takemura, Y. Matsumoto, Dissolution rate of spherical carbon dioxide bubbles in strong alkaline solutions, Chem. Eng. Sci. 55 (2000) 3907-3917.

[38] V.A. Juvekar, M.M. Sharma, Absorption of $\mathrm{CO}_{2}$ in a suspension of lime, Chem. Eng. Sci. 28 (1973) 825-837.

[39] J.D. Rodriguez-Blanco, S. Shaw, P. Bots, T. Roncal-Herrero, L.G. Benning, The role of $\mathrm{pH}$ and $\mathrm{Mg}$ on the stability and crystallization of amorphous calcium carbonate, J. Alloys Compd. 536 (2012) S477-S479.
[40] E. Chibowski, L. Holysz, W. Wójcik, Changes in zeta potential and surface free energy of calcium carbonate due to exposure to radiofrequency electric field, Coll. Surf. A 92 (1994) 79-85.

[41] M. Xu, X.M. Hu, K.G. Knauss, S.R. Higgins, Dissolution kinetics of calcite at $50-70^{\circ} \mathrm{C}$ : An atomic force microscopic study under near-equilibrium conditions, Geochim. Cosmochim. Acta 74 (2010) 4285-4297.

[42] J. Rieger, J. Thieme, C. Schmidt, Study of precipitation reactions by X-ray microscopy: caCO3 precipitation and the effect of polycarboxylates, Langmuir 16 (2000) 8300-8305

[43] M. Schmidt, T. Stumpf, C. Walther, H. Geckeis, T. Fanghanel, Phase transformation in $\mathrm{CaCO} 3$ polymorphs: a spectroscopic, microscopic and diffraction study, J. Colloid Interface Sci. 351 (2010) 50-56.

[44] B. Beskova, M. Starkova, E. Sarka, J. Gojny, Z. Bubnik, Application of carbonatation lime as a filler for adhesives, Zuckerindustrie 134 (2009) 486-490.

[45] J.S.D. Campos, A.A. Ribeiro, C.X. Cardoso, Preparation and characterization of PVDF/CaCO3 composites, Mater. Sci. Eng. B: Solid 136 (2007) 123-128.

[46] T.D. Lam, T.V. Hoang, D.T. Quang, J.S. Kim, Effect of nanosized and surface-modified precipitated calcium carbonate on properties of CaCO3/polypropylene nanocomposites, Mater. Sci. Eng. A: Struct. 501 (2009) $87-93$

[47] Y. Sheng, J.Z. Zhao, B. Zhou, X.F. Ding, Y.H. Deng, Z.C. Wang, In situ preparation of CaCO3/polystyrene composite nanoparticles, Mater. Lett. 60 (2006) 3248-3250.

[48] L. Sorrentino, F. Berardini, M.R. Capozzoli, S. Amitrano, S. Iannace, Nano/micro ternary composites based on PP, nanoclay, and CaCO3, J. Appl. Polym. Sci. 113 (2009) 3360-3367.

[49] Y. Wen, L. Xiang, Y. Jin, Synthesis of plate-like calcium carbonate via carbonation route, Mater. Lett. 57 (2003) 2565-2571.

[50] T. Ikoma, T. Tonegawa, H. Watanaba, G.P. Chen, J. Tanaka, Y. Mizushima, Drug-supported microparticles of calcium carbonate nanocrystals and its covering with hydroxyapatite, J. Nanosci. Nanotechnol. 7 (2007) 822-827.

[51] D. Preisig, D. Haid, F.J.O. Varum, R. Bravo, R. Alles, J. Huwyler, M. Puchkov, Drug loading into porous calcium carbonate microparticles by solvent evaporation, Eur. J. Pharm. Biopharm. 87 (2014) 548-558.

[52] A.A. Weiner, D.M. Shuck, J.R. Bush, V.P. Shastri, In vitro degradation characteristics of photocrosslinked anhydride systems for bone augmentation applications, Biomaterials 28 (2007) 5259-5270.

[53] Y. Zhao, Z. Luo, M.H. Li, Q.Y. Qu, X. Ma, S.H. Yu, Y.L. Zhao, A preloaded amorphous calcium carbonate/doxorubicin@silica nanoreactor for pH-responsive delivery of an anticancer drug, Angew. Chem. Int. Edit. 54 (2015) 919-922. 